\title{
Neutron Emission Characteristics of Two Mixed-Oxide Fuels: Simulations and Initial Experiments
}

D. L. Chichester

S. A. Pozzi

J. L. Dolan

M. Flaska

J. T. Johnson

E. H. Seabury

E. M. Gantz

July 2009

The INL is a U.S. Department of Energy National Laboratory operated by Battelle Energy Alliance

Idaho National 
INL/EXT-09-16566

\title{
Neutron Emission Characteristics of Two Mixed-Oxide Fuels: Simulations and Initial Experiments
}

\author{
D. L. Chichester \\ S. A. Pozzi ${ }^{1}$ \\ J. L. Dolan ${ }^{1}$ \\ M. Flaska ${ }^{1}$ \\ J. T. Johnson \\ E. H. Seabury \\ E. M. Gantz \\ ${ }^{1}$ University of Michigan \\ July 2009

\section{Idaho National Laboratory \\ Idaho Falls, Idaho 83415} \\ http://www.inl.gov \\ Prepared for the \\ U.S. Department of Energy \\ Office of Nuclear Energy \\ Under DOE Idaho Operations Office \\ Contract DE-AC07-05ID14517
}




\section{DISCLAIMER}

This information was prepared as an account of work sponsored by an agency of the U.S. Government. Neither the U.S. Government nor any agency thereof, nor any of their employees, makes any warranty, expressed or implied, or assumes any legal liability or responsibility for the accuracy, completeness, or usefulness, of any information, apparatus, product, or process disclosed, or represents that its use would not infringe privately owned rights. References herein to any specific commercial product, process, or service by trade name, trade mark, manufacturer, or otherwise, do not necessarily constitute or imply its endorsement, recommendation, or favoring by the U.S. Government or any agency thereof. The views and opinions of authors expressed herein do not necessarily state or reflect those of the U.S. Government or any agency thereof. 


\title{
Neutron Emission Characteristics of Two Mixed-Oxide Fuels: Simulations and Initial Experiments
}

\author{
D. L. Chichester ${ }^{1}$, S. A. Pozzi ${ }^{2}$, J. L. Dolan ${ }^{2}$, M. Flaska ${ }^{2}$, \\ J. T. Johnson ${ }^{1}$, E. H. Seabury ${ }^{1}$, and E. M. Gantz ${ }^{1}$ \\ ${ }^{1}$ Idaho National Laboratory, Idaho Falls, ID 83415 \\ ${ }^{2}$ Department of Nuclear Engineering \& Radiological Sciences, \\ University of Michigan, Ann Arbor, MI 48109
}

\begin{abstract}
Simulations and experiments have been carried out to investigate the neutron emission characteristics of two mixed-oxide (MOX) fuels at Idaho National Laboratory (INL). These activities are part of a project studying advanced instrumentation techniques in support of the U.S. Department of Energy's Fuel Cycle Research and Development program and its Materials Protection, Accounting, and Control for Transmutation (MPACT) campaign. This analysis used the MCNP-PoliMi Monte Carlo simulation tool to determine the relative strength and energy spectra of the different neutron source terms within these fuels, and then used this data to simulate the detection and measurement of these emissions using an array of liquid scintillator neutron spectrometers. These calculations accounted for neutrons generated from the spontaneous fission of the actinides in the MOX fuel as well as neutrons created via $(\alpha, n)$ reactions with oxygen in the MOX fuel. The analysis was carried out to allow for characterization of both neutron energy as well as neutron coincidences between multiple detectors. Coincidences between prompt gamma rays and neutrons were also analyzed. Experiments were performed at INL with the same materials used in the simulations to benchmark and begin validation tests of the simulations. Data was collected in these experiments using an array of four liquid scintillators and a high-speed waveform digitizer. Advanced digital pulse-shape discrimination algorithms were developed and used to collect this data. Results of the simulation and modeling studies are presented together with preliminary results from the experimental campaign.
\end{abstract}

\section{Introduction}

Advanced nuclear fuels are currently under development within the Department of Energy's Fuel Cycle Research and Development program as part of a long-term research effort focused at understanding the behavior of mixed-oxide (MOX) fuels containing minor actinides and long-lived fission products. The aim of this work is to understand how these materials impact the long-term performance of nuclear fuel in order to be able to design and manufacture advanced fuels for use in next-generation reactors. Reusing, or recycling, the higher actinides and long-lived fission products in advanced nuclear fuels ultimately leads to the transmutation of these materials into shorter-lived waste products which may be more easily and more safely disposed of. There are several potential benefits of reusing nuclear fuel including the reclamation of additional energy content from once-through used fuels, the reduction or removal of longer-lived waste products from spent fuel, and the lessening of the storage demands eventually placed on facilities for the long-term storage or disposal of spent fuels. In parallel with the fuel 
development projects research and development is also underway to develop advanced fuel reprocessing approaches to produce these fuels and to develop advanced reactors to use these fuels. However, in addition to these core engineering research and development projects the ultimate viability of these new technology developments will be critically linked to advances in the fields of nuclear safeguards and material protection, control, and accounting (MPC\&A).

Traditional nuclear safeguard measurement techniques used to monitor uranium oxide fuels are not well-suited for analyzing advanced MOX fuels. Gross gamma-ray counting is complicated by the presence of the additional radioactive materials in the fuel while high-resolution gamma-ray spectroscopy can be difficult to perform due to the presence of multiple interferences associated with the presence of the minor actinides. Similarly, the powerful passive and active neutron-based nondestructive assay techniques used with current-generation fresh and irradiated commercial nuclear fuel are complicated by the presence of multiple higher actinides, some of which have spontaneous fission and induced fission signatures comparable to plutonium.

This report summarizes scoping studies, including modeling, simulations, and validation experiments, examining the feasibility and utility of neutron-based characterization methods for analyzing MOX fuels. Important aspects of long-term, science-based research and development (R\&D) include small-scale experiments, theory development, and advanced modeling and simulation with validation experiments; this project embraces this paradigm for the "science-based" R\&D approach. Starting in the autumn of 2008 a collaboration was established between researchers in INL's Nuclear Nonproliferation Division and the Detection for Nonproliferation Group in the Department of Nuclear Engineering \& Radiological Sciences at the University of Michigan.

Supported by the U.S. Department of Energy's Fuel Cycle Research and Development program and it's Materials Protection, Accounting, and Control for Transmutation (MPACT) campaign, this research has used the MCNP-PoliMi Monte Carlo simulation tool to determine the relative strength and energy spectra of the different neutron source terms within two MOX fuels, and then used this data to simulate the detection and measurement of these emissions using an array of liquid scintillator neutron spectrometers. These calculations accounted for neutrons generated from the spontaneous fission of the actinides in the MOX fuel as well as neutrons created via $(\alpha, n)$ reactions with oxygen in the MOX fuel. The analysis was carried out to allow for characterization of both neutron energy as well as neutron coincidences between multiple detectors. Coincidences between prompt gamma rays and neutrons were also analyzed. Following these simulations, experiments were performed at INL using materials which were the basis for the those used in the simulations together with an array of four liquid scintillators and a high-speed waveform digitizer. Advanced digital pulse-shape discrimination algorithms were developed and used to collect this data. This report summarizes these activities and provides a comprehensive discussion of the initial phase of the project in the form of paper published as an INL report (see the Appendix) intended for publication in the Journal of Nuclear Materials Management.[1] A second report, detailing the results of the validation experiment at INL, is currently being prepared and will be available in October 2009. 


\section{Active Interrogation to Detect Undeclared Materials}

Idaho National Laboratory possess a diverse variety of special nuclear materials useful for validating passive screening and active interrogation nondestructive analysis techniques for nuclear safeguards and MPC\&A.[2,3] For this project five MOX fuel materials were selected from the inventory for consideration, Table 1.

Table 1 Five MOX fuel element materials studied in this project [3]

\begin{tabular}{|c|c|c|c|c|c|}
\hline ID No. & 127 & 128 & 129 & 219 & 220 \\
\hline Size & $\begin{array}{c}0.9525 \mathrm{~cm} \\
\varnothing \times 15.24 \\
\mathrm{~cm} \text { long }\end{array}$ & $\begin{array}{c}0.9525 \mathrm{~cm} \\
\varnothing \times 15.24 \\
\mathrm{~cm} \text { long }\end{array}$ & $\begin{array}{c}0.9525 \mathrm{~cm} \\
\varnothing \times 15.24 \\
\mathrm{~cm} \text { long }\end{array}$ & $\begin{array}{c}0.9525 \mathrm{~cm} \\
\varnothing \times 7.62 \\
\mathrm{~cm} \text { long }\end{array}$ & $\begin{array}{c}0.9525 \mathrm{~cm} \\
\varnothing \times 7.62 \\
\mathrm{~cm} \text { long }\end{array}$ \\
\hline Average weight & 101.9437 & 101.6026 & 105.6026 & 46.6729 & 46.5390 \\
\hline Core weight & 89.5527 & 89.2310 & 89.7760 & 39.7282 & 39.5746 \\
\hline Pu weight & 11.7370 & 23.5272 & 14.0147 & 5.2856 & 10.4948 \\
\hline${ }^{238} \mathrm{Pu}$ & 0.0095 & 0.0095 & 0.0096 & 0.0000 & 0.0096 \\
\hline${ }^{239} \mathrm{Pu}$ & 10.1906 & 20.4344 & 9.8079 & 4.5965 & 9.1074 \\
\hline${ }^{240} \mathrm{Pu}$ & 1.3644 & 2.7244 & 3.6603 & 0.6096 & 1.2189 \\
\hline${ }^{241} \mathrm{Pu}$ & 0.1524 & 0.3114 & 0.5170 & 0.0694 & 0.1389 \\
\hline${ }^{242} \mathrm{Pu}$ & 0.0200 & 0.0474 & 0.0200 & 0.0100 & 0.0200 \\
\hline${ }^{241} \mathrm{Am}$ & 0.0544 & 0.1013 & 0.1473 & 0.0205 & 0.0410 \\
\hline U weight & 66.9038 & 54.8726 & 64.5849 & 29.6244 & 24.2600 \\
\hline${ }^{235} \mathrm{U}$ & 0.1502 & 0.1172 & 0.1391 & 0.0700 & 0.0500 \\
\hline${ }^{238} \mathrm{U}$ & 66.7536 & 54.7554 & 64.4458 & 29.5544 & 24.2100 \\
\hline 0 weight & 10.5746 & 10.4760 & 10.5936 & 4.6610 & 4.6769 \\
\hline Clad weight & 12.39 & 12.37 & 12.39 & 6.94 & 6.97 \\
\hline 69.53 wto $\mathrm{Fe}$ & 8.615 & 8.601 & 8.615 & 4.825 & 4.846 \\
\hline 18.54 wt $\% \mathrm{Cr}$ & 2.297 & 2.293 & 2.297 & 1.287 & 1.292 \\
\hline wt\% $\mathrm{Ni}$ & 1.196 & 1.194 & 1.196 & 0.670 & 0.673 \\
\hline 1.28 wt $\% \mathrm{Mn}$ & 0.159 & 0.158 & 0.159 & 0.089 & 0.089 \\
\hline 0.47 wt\% $\mathrm{Si}$ & 0.058 & 0.058 & 0.058 & 0.033 & 0.033 \\
\hline wt\% Co & 0.011 & 0.011 & 0.011 & 0.006 & 0.006 \\
\hline 0.06 wt $\%$ Mo & 0.007 & 0.007 & 0.007 & 0.004 & 0.004 \\
\hline 0.06 wt $\% \mathrm{Cu}$ & 0.007 & 0.007 & 0.007 & 0.004 & 0.004 \\
\hline 0.05 wt\% $\mathrm{Ti}$ & 0.006 & 0.006 & 0.006 & 0.003 & 0.003 \\
\hline 0.035 wt\% $\mathrm{Al}$ & 0.004 & 0.004 & 0.004 & 0.002 & 0.002 \\
\hline 0.028 wt\% $\mathrm{C}$ & 0.003 & 0.003 & 0.003 & 0.002 & 0.002 \\
\hline 0.02 wt\% $\mathrm{Ta}$ & 0.002 & 0.002 & 0.002 & 0.001 & 0.001 \\
\hline 0.014 wt $\% \mathrm{P}$ & 0.002 & 0.002 & 0.002 & 0.001 & 0.001 \\
\hline 0.01 wt $\% \mathrm{Be}$ & 0.001 & 0.001 & 0.001 & 0.001 & 0.001 \\
\hline 0.007 wt $\% \mathrm{~S}$ & 0.001 & 0.001 & 0.001 & 0.001 & 0.001 \\
\hline
\end{tabular}

Note: Isotopic content as of July 1, 1983.

\section{Simulation and Modeling}

Starting with the five fuel types presented in Table 1 models were developed by the University of Michigan team, using the MCNP-PoliMi Monte Carlo radiation transport code, to evaluate the neutron emission characteristics from $10 \times 10$ square-array assemblies of each type of fuel pin.[4] Simple results describing the contribution of the 
different source terms to the total neutron contribution from each assembly are shown in Figure 1 through Figure 5. In all cases the spontaneous fission of ${ }^{240} \mathrm{Pu}$ is the dominant source of neutrons. However, the creation of neutrons via $(\alpha, n)$ reactions with oxygen in the fuel matrix is significant in these materials as well. A plot of the neutron energy distribution from each of the separate sources for the ID No. 127 material is shown in Figure 6; in contrast with the wide energy fission spectrum distributions the neutrons created via $(\alpha, n)$ reactions are roughly centered around $2.5 \mathrm{MeV}$ and do not extend to energies higher than $4.5 \mathrm{MeV}$. This is important because it shows the possibility of determining the chemical form of plutonium bearing matrices based upon coarse neutron spectra measurements.[5] Extending this idea further, data is presented in Figure 7 to illustrate how the neutron spectrum differs for different sized arrays of fuel pins of material 127. Resonant scattering in the oxygen matrix of these fuels has a pronounced effect on the energy distribution of the emitted neutrons. Neutron spectroscopy in some cases may be useful for not only determining material matrices for plutonium (oxide versus metal) but, in conjunction with supporting information, may also be useful in mass determinations in cases with known, pre-defined geometries.

Figure 1 The neutron source term for a 100 pin array of fuel: ID No. 127

\section{INL Project Background Fuel Pin Composition-127 \\ (1)}

$13.1 \%$ Plutonium by weight

\section{Fuel Rod 127}

Polimi Code

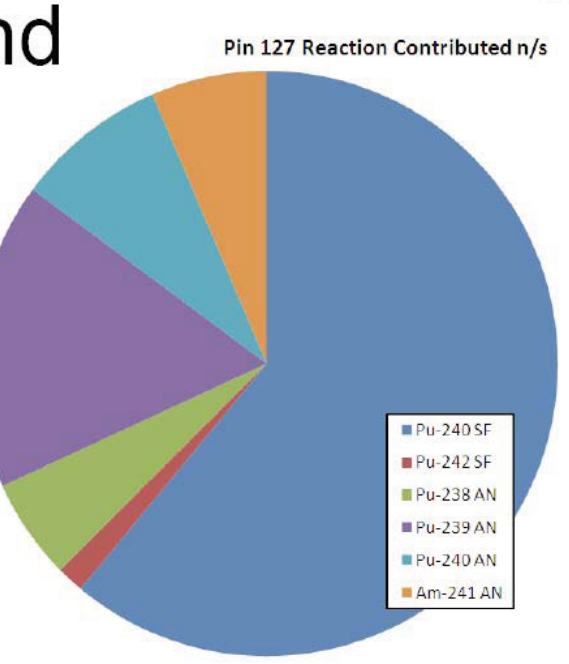

[n/s]
1391.7
34.4
127.3
388.3
192.4
146.3

[n/fis]

2.16

2.15

[Reactions/s] 644.3

16.0

127.3

388.3

192.4

146.3
Reaction

Probability

0.4

0.01

0.08

0.3

0.1 
Figure 2 The neutron source term for a 100 pin array of fuel: ID No. 128

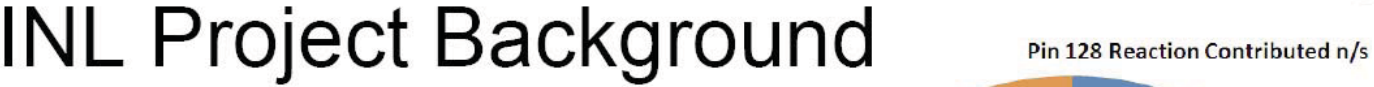 Fuel Pin Composition-128 \\ . \\ (1)}

$26.4 \%$ Plutonium by weight
Fuel Pin 128

Polimi Code

3

38

38
39

40

41
PU-240 SF

PU-242 SF

Pu-238 AN

Pu-239 AN

Pu-240 AN

Am-241 AN

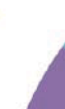

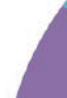

Figure 3 The neutron source term for a 100 pin array of fuel: ID No. 129

\section{INL Project Background Fuel Pin Composition-129}

$15.6 \%$ Plutonium by weight

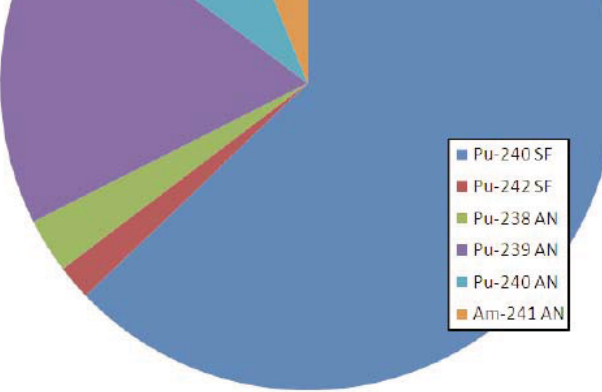

$[\mathrm{n} / \mathrm{s}]$
2778.9
81.5
127.3
778.6
384.1
272.5

$\begin{array}{ccc}\text { [n/fis] } & \text { [Reactions/s] } & \begin{array}{c}\text { Reaction } \\ \text { Probability }\end{array} \\ 2.16 & 1286.5 & 0.4 \\ 2.15 & 37.9 & 0.01 \\ & 127.3 & 0.04 \\ & 778.6 & 0.3 \\ & 384.1 & 0.1 \\ & 272.5 & 0.09\end{array}$

Fuel Rod 129

$\begin{array}{ccc}\text { Polimi Code } & & \text { Wt. [g] } \\ 3 & \text { Pu-240 SF } & 3.66 \\ 4 & \text { Pu-242 SF } & 0.02 \\ 38 & \text { Pu-238 AN } & 0.01 \\ 39 & \text { Pu-239 AN } & 9.81 \\ 40 & \text { Pu-240 AN } & 3.66 \\ 41 & \text { Am-241 AN } & 0.15\end{array}$

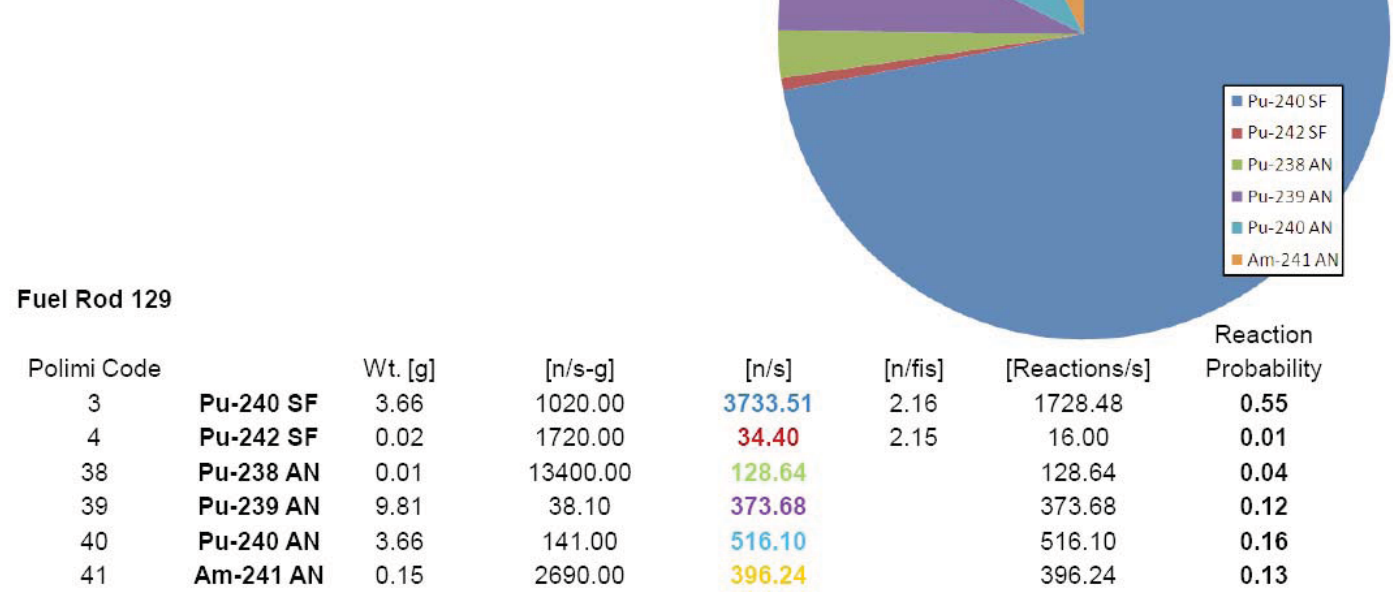


Figure 4 The neutron source term for a 100 pin array of fuel: ID No. 219

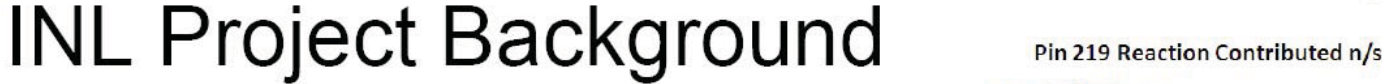 Fuel Pin Composition-219 \\ .}

$13.3 \%$ Plutonium by weight

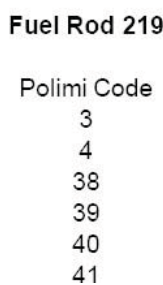

41

\section{(1)}


Figure 6 Neutron energy distribution from the separate neutron source terms of fuel ID No. 127, presented in Figure 1

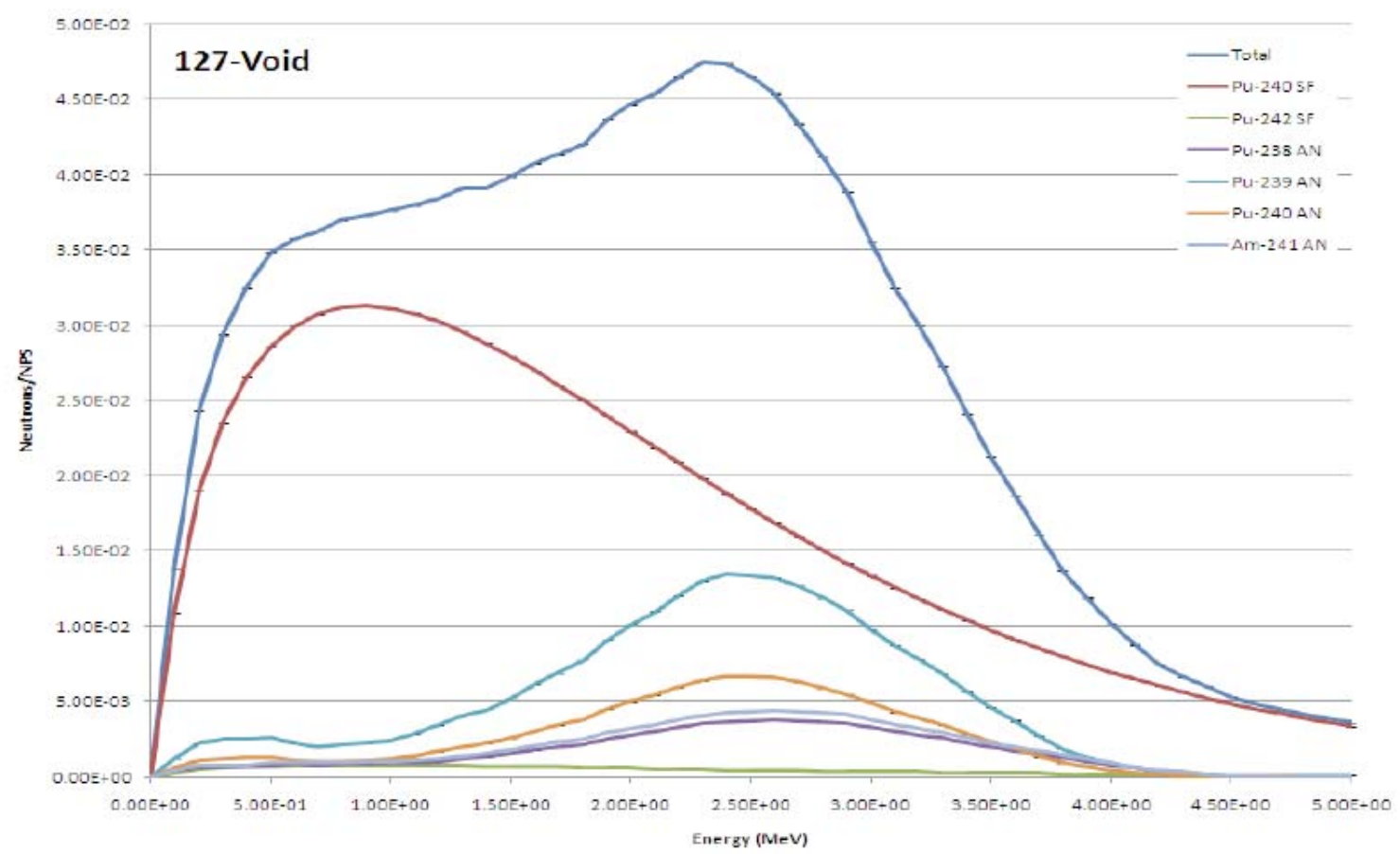

Figure 7 Neutron spectrum from different sized arrays of fuel 127 together with the cross section for neutron scattering in oxygen (inset: red $=$ elastic, blue $=$ total)

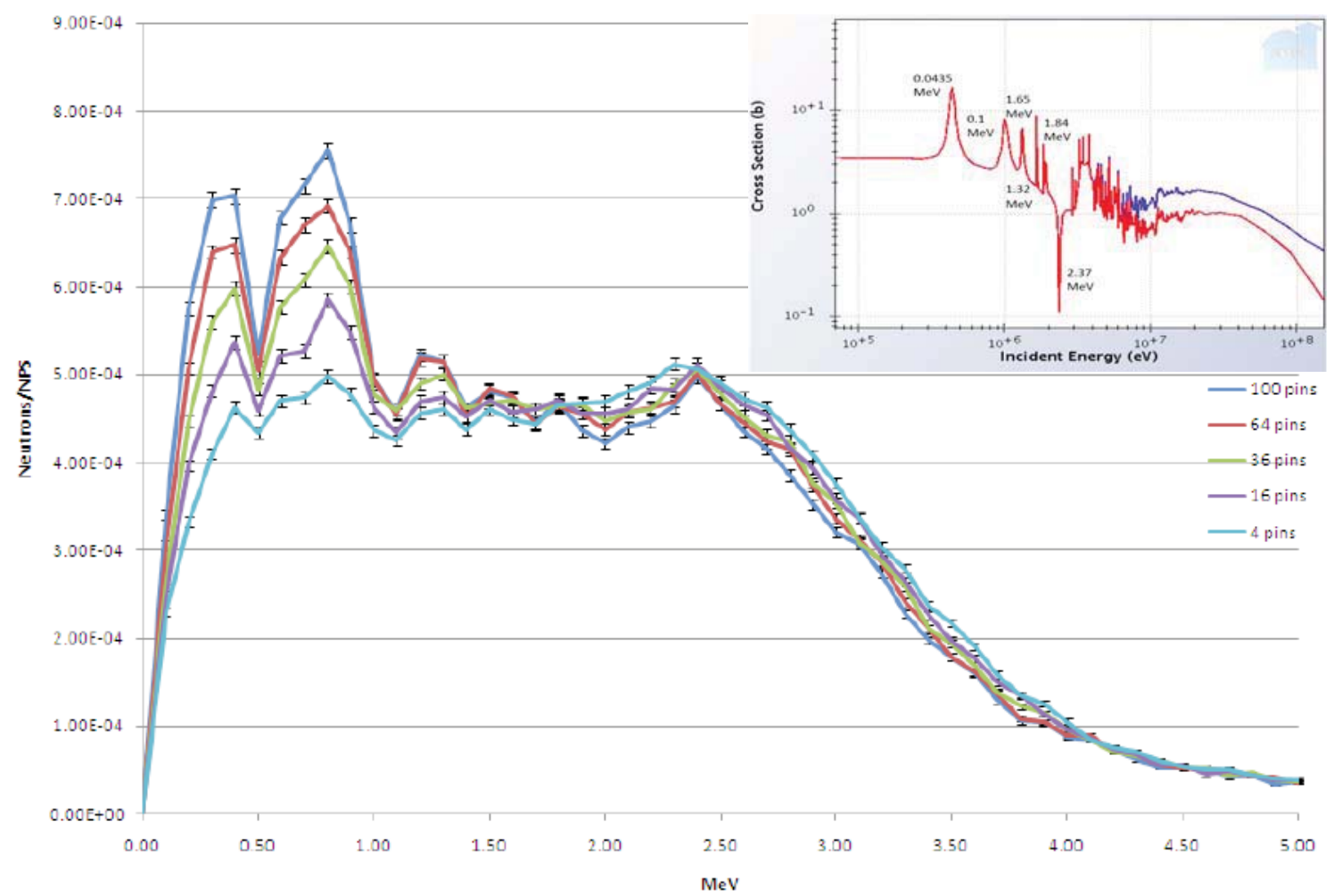


In addition to modeling and analyzing significant features of the neutron spectra from these different fuels, simulations were also carried out to investigate neutronneutron and neutron-gamma ray correlations for measurements of MOX fuel. As an example, simulation data is shown in Figure 8 to illustrate the time-of-flight neutron and gamma-ray data for detection events in a liquid scintillator following fission in ${ }^{240} \mathrm{Pu}$. Coincident with the fission event an intense prompt gamma-ray signature is observed, followed by the detection of neutrons in the detector starting with the highest energy (fastest) neutrons which are then preceded with the balance of the slower neutrons from the fission process and scattered neutrons. In Figure 9 simulation data is presented showing the time-dependent cross-correlation signature from the natural neutron and gamma-ray emission of a 100 pin array of ID No. 127 MOX fuel pins. Gamma-ray coincidences occur within a narrow peak near zero in the plot while neutron-neutron coincidences occur over a much broader time period, due to the their slower energy (relative to the speed of light) and broader energy distribution. Photon-neutron coincidences appear offset from time zero in these plots due to the relative difference in particle speed between the two quanta and the subsequent difference in detection time between registration of a gamma ray in one detector and later (or prior) detection of a neutron in a different detector.

A comprehensive summary of the simulation and modeling performed in support of this project is provided in the APPENDIX of this report.

Figure 8 Time-of-flight correlation simulation for events from the spontaneous fission of ${ }^{240} \mathrm{Pu}$ in a square array of 100 pins of fuel No. 127 measured using liquid scintillator detectors $60 \mathrm{~cm}$ from the fuel. (This simulation did not include postfission neutron scattering or capture events on the matrix.)

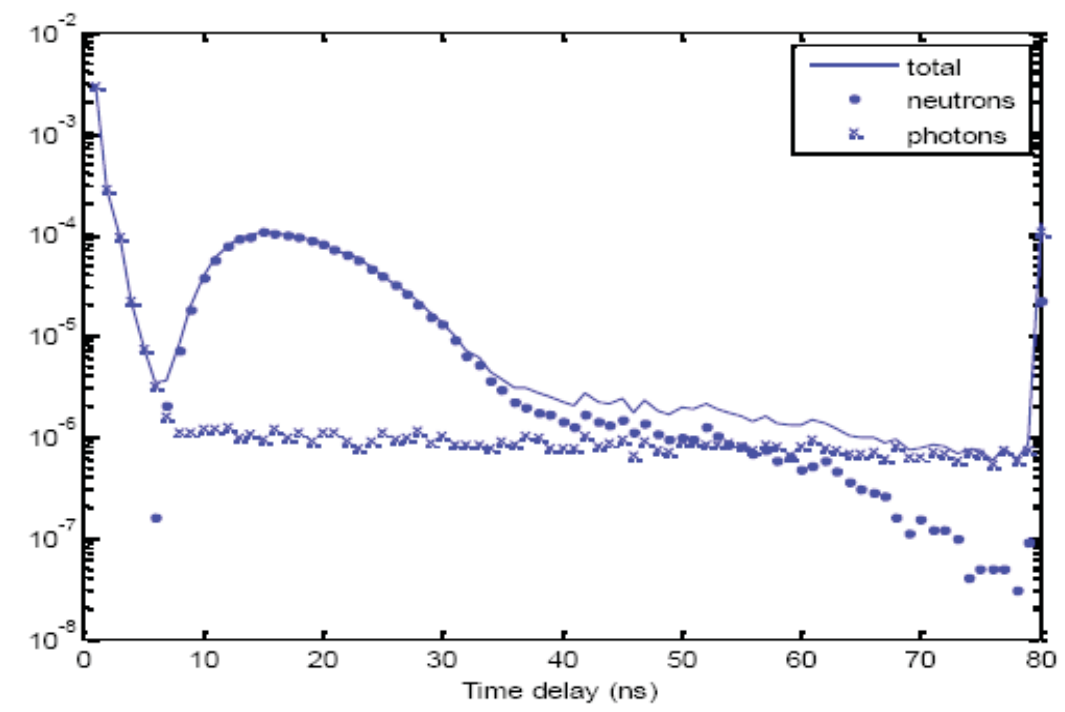


Figure 9 Plot of the simulation of the cross-correlation signal for opposed liquid scintillator neutron spectrometers measuring neutrons and gamma rays from a 100 pin array of fuel No. 127

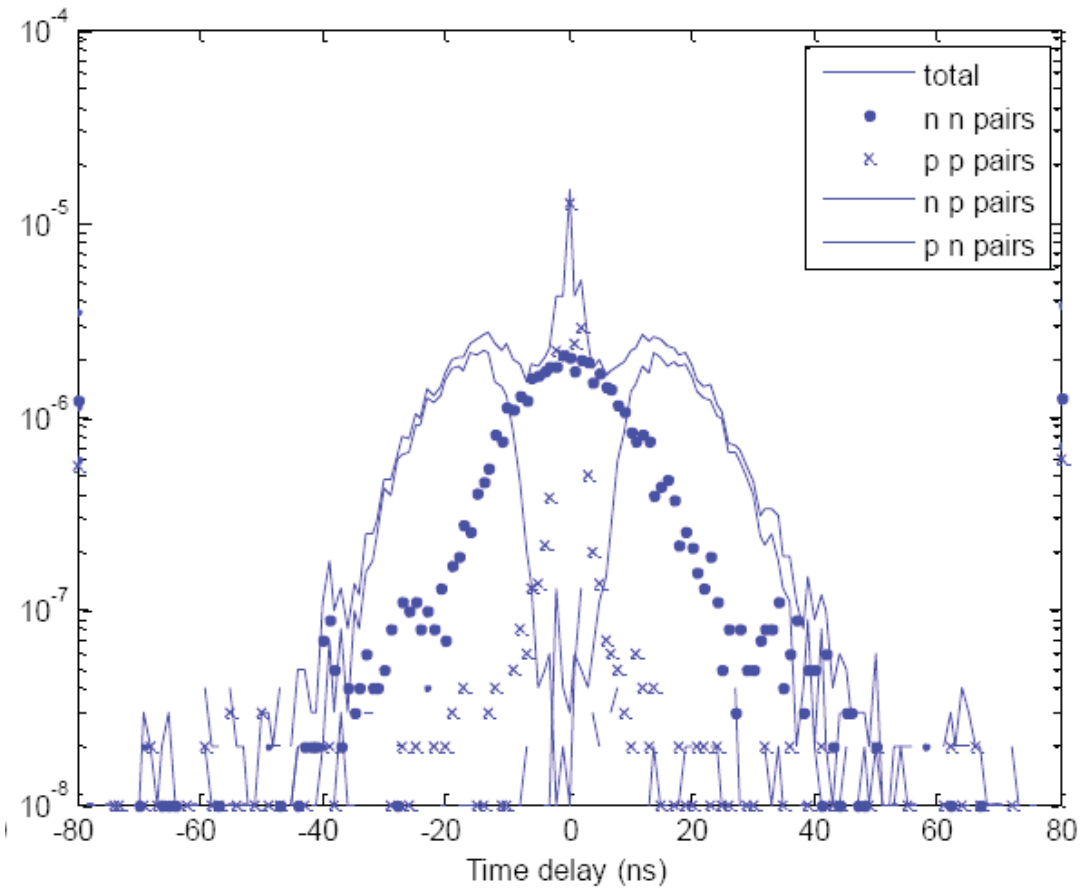

\section{Validation Experiments}

During the week of June 22 experiments were carried out at INL using four liquid scintillator detectors and three assemblies of MOX fuel. The detectors used in these experiments used EJ-309 liquid scintillator made by Eljen Technologies. Data was collected using a 12-bit waveform digitizer sampling data at $250-\mathrm{MHz}$ and stored to a personal computer in list mode format for post processing and analysis. The gain for the four photomultiplier tubes was adjusted and matched using a ${ }^{137} \mathrm{Cs}$ check source.

The fuel used in these experiments consisted of two circular arrays of fuel 127, one containing 90 pins and the other containing 45 pins, and one array containing 100 pins of fuel 129. All three samples were sealed within sealable storage cans. A photograph of the inside of a can with a 90 pin array is shown in Figure 10, photos of the 45 pin array are shown in Figure 11. The four detectors were set-up on tables inside INL's ZPPR facility workroom, arranged in a square. The detector-fuel spacing could be adjusted from $20 \mathrm{~cm}$ to $80 \mathrm{~cm}$. Lead bricks were placed at the front face of each detector to provide $5.08 \mathrm{~cm}$ of shielding. This shielding was needed because of the high photon emission rate of the fuel samples. The on-contact photon dose rate exceeded $>400$ $\mathrm{mrem} / \mathrm{hr}$ for the can with 100 pins of high burn-up fuel; the neutron dose rate for that same can was approximately $20 \mathrm{mrem} / \mathrm{hr}$. A photograph of the layout for these experiments is shown in Figure 12. For some measurements the cans were laid sideways on the support foam. 
Figure 10 An array of 90 pins of MOX fuel loaded in a round can.

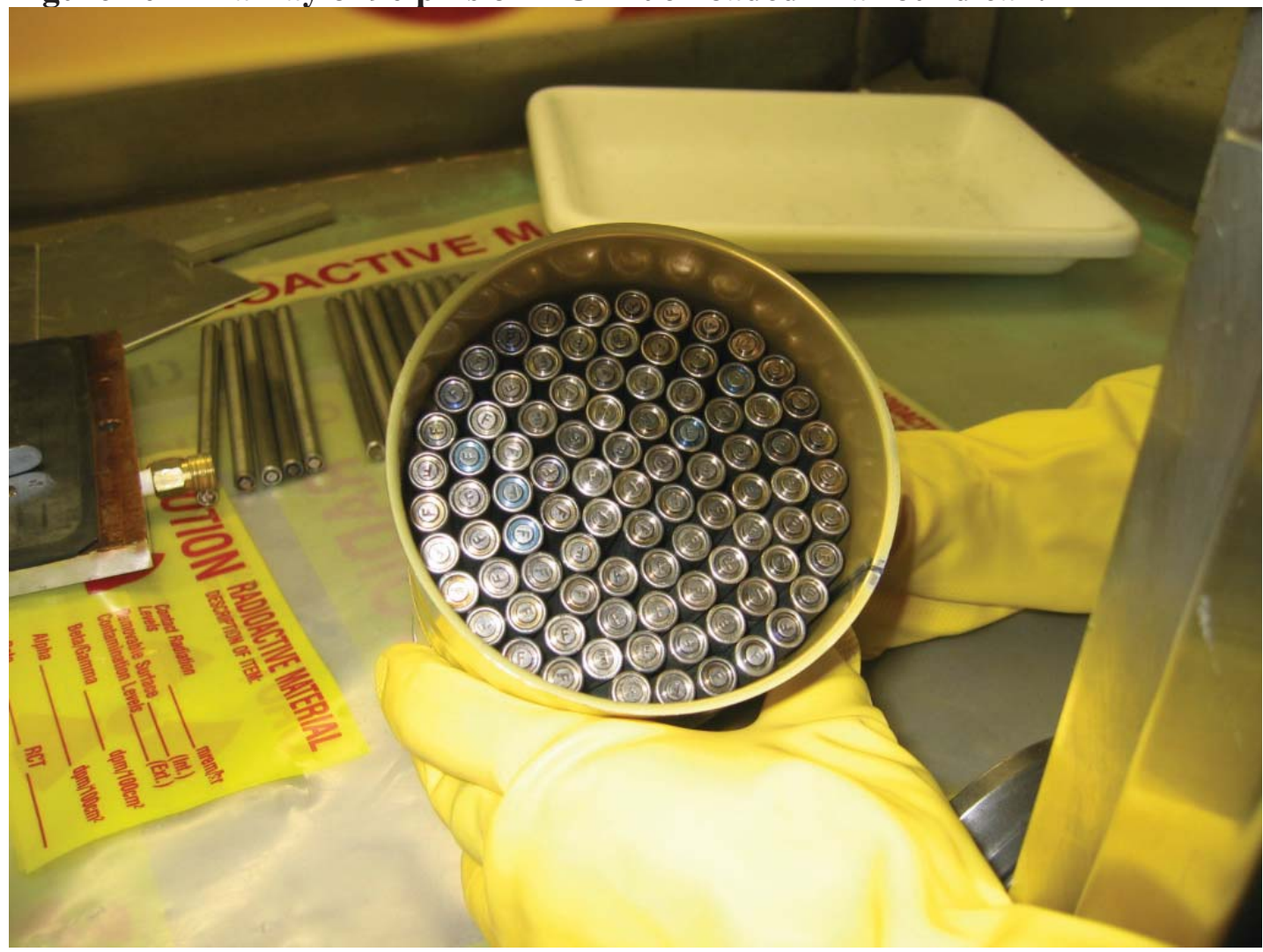

Figure 11 An array of 45 pins of MOX on the bench (left) and positioned inside a round can with aluminum foil to keep it centered (right).

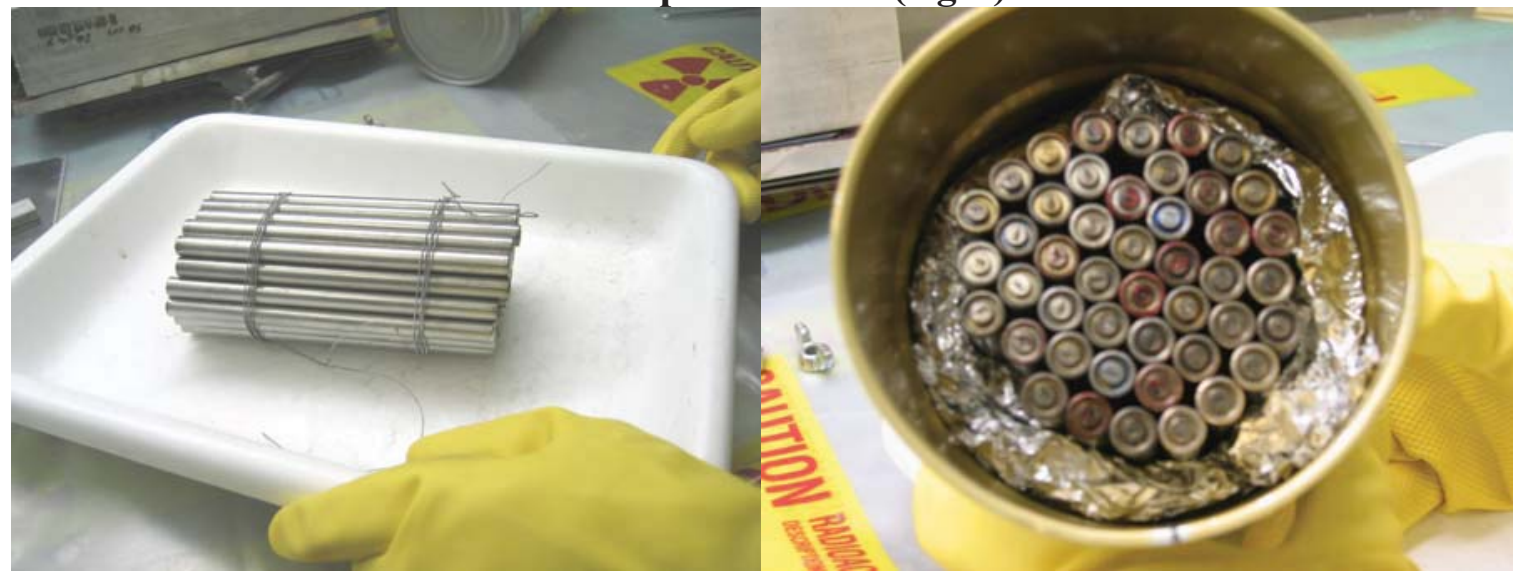


Figure 12 Photograph of the typical experimental layout for the tests described here.

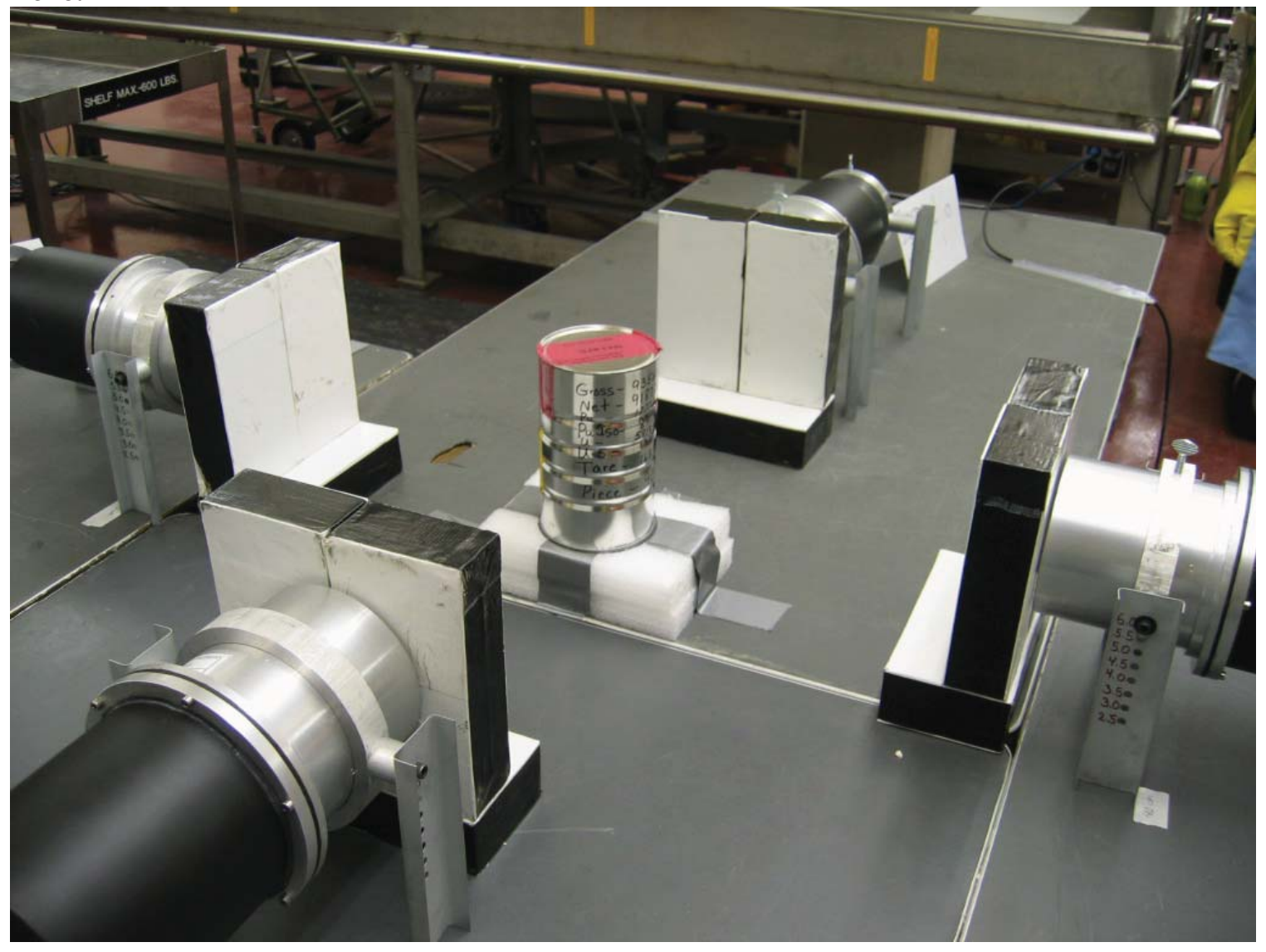

Experiments were carried out over three days; over 220 gigabytes of data were taken. Analysis of this data is currently underway and will be presented this autumn at the Institute of Electrical and Electronics Engineers (IEEE) Nuclear Science Symposium. Preliminary analysis of the data indicates good agreement between simulation and experiments for the neutron-neutron coincidence time correlation, as shown in Figure 13. Unfortunately, the background rate associated with the photon based coincidence data is quite high, despite using the lead shielding in these experiments. Further analysis is underway to understand this and to evaluate alternate approaches for dealing with high background photon count rates in the future. 
Figure 13 Comparison of simulated and experimental data for evaluating neutronneutron coincidences.

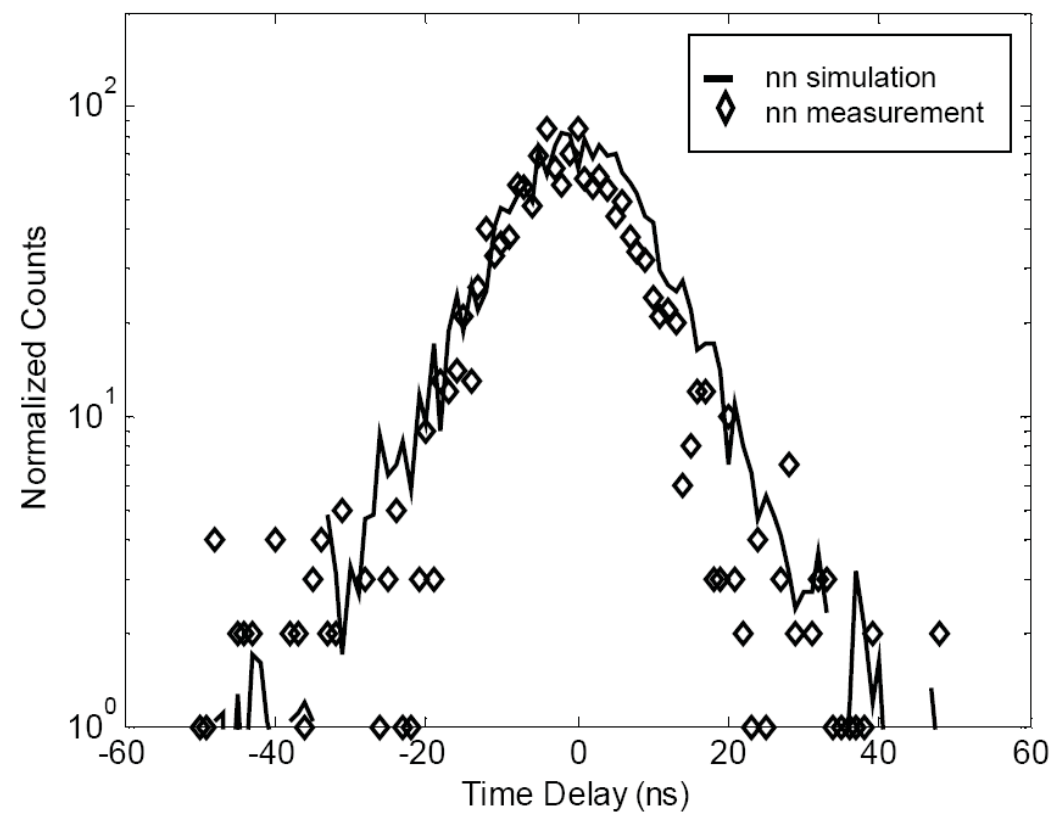

\section{Summary}

Scoping studies using simulation tools and small-scale validation experiments have been carried out to investigate the use of neutron spectroscopy and neutron coincidence analysis methods to identify and characterize MOX fuel. This exploratory work is beginning at a fundamental level, building both simulation tools and experimental capabilities in parallel, to support long-range research in the areas of safeguards and MPC\&A for the Fuel Cycle Research and Development program. The ultimate goal of this program is the development of an advanced-fuel analysis technique for assaying advanced MOX fuel incorporating minor actinides and long-lived fission products. This research project supports the Fuel Cycle program by investigating nondestructive techniques for analyzing MOX materials which will be encountered in next-generation fuel reprocessing facilities.

During the current year of research the project has focused on developing simulation capabilities and understanding the underlying phenomena impacting the neutron signatures of MOX fuels. Simulation results indicate low-resolution neutron spectroscopy may be useful for verifying the matrix form of neutron emitting materials such as MOX fuel while higher resolution neutron spectroscopy may provide a tool for determining or verifying material mass and geometry under certain conditions. Experiments have been carried out to collect validation data to support the scientific understanding and modeling of these processes. Preliminary analysis of the data has shown reasonable agreement but has also highlighted the need to incorporate additional phenomena into the models. The experimental campaign has also provided insight into some important challenges that need to be addressed for future activities.

In the next year of the project work will continue to develop and strengthen our scientific understanding of these phenomena and prepare for more complicated modeling using representative advanced MOX fuel compositions, spent fuel, and other advanced 
fuel forms. In addition, the project will expand to begin simulations and experimental analyses in active interrogation measurements. Active interrogation can be used to increase the intensity and number of signatures from special nuclear material, prior work in the area has demonstrated the value of using active interrogation for assaying spent fuel.[ 6 - 10]

\section{Acknowledgement}

The authors would like to acknowledge and thank the staff at INL's Materials and Fuels Complex and the ZPPR facility for their support and enthusiasm for the experiments described in this report. The work in this report was sponsored by the U.S. Department of Energy's Fuel Cycle Research and Development program and its Materials Protection, Accounting, and Control for Transmutation (MPACT) campaign. Additional support was also provided by INL in the form of Laboratory Directed Research and Development funds from INL's Nuclear Nonproliferation Initiative. 


\section{References}

1 Dolan, J. L., Flaska, M., Pozzi, S. A., and Chichester, D. L., " Measurement and Characterization of Nuclear Material at Idaho National Laboratory," Report INL/CON-09-16103, Idaho National Laboratory, Idaho Falls, Idaho (2009).

2 Chichester, D. L., Seabury, E. H., Turnage, J. A., Brush, B. A., and Perry, E. F., "Capabilities of the INL ZPPR to Support Active Interrogation Research with SNM," AIP Conf. Proc. 1099 (2009) 647-651.

3 Klann, R. T. Austin, B. D., Aumeier, S. E., and Olsen, D. N., "Inventory of Special Nuclear Materials from the Zero Power Physics Reactor," Report ANL-NT-176, Argonne National Laboratory-West, Idaho Falls, Idaho (2001).

4 Pozzi, S. A., Padovani, E., and Marseguerra, M., "MCNP-PoliMi: A Monte Carlo Code for Correlation Measurements," Nucl. Inst. Meth. Phys. Res. A 513 (2003) 550558.

5 Shores, E. F., "Plutonium Oxide Benchmark Problems for the SOURCES Code," App. Rad. Iso. 62 (2005) 699-704.

6 Krinninger, H., et al., "Pulsed Neutron Method for Non-destructive and Simultaneous Determination of the ${ }^{235} \mathrm{U}$ And ${ }^{239} \mathrm{Pu}$ Contents of Irradiated and Non-irradiated Reactor Fuel Elements," Nucl. Inst . Meth. 73 (1969) 13-33.

7 Gozani, T., "Non Destructive Assay of Spent Fuel for Determination of Residual Fissile Content," J. Inst. Nucl. Mat. Management 5 (1976) 514-524.

8 Hsue, S. T., et al., "Nondestructive Assay Methods for Irradiated Nuclear Fuels," Report LA-6923, Los Alamos National Laboratory, Los Alamos, NM (1978).

9 Eccleston, G. W. and Menlove, H. O., "A Measurement System for High Enriched Spent Fuel Assemblies and Waste Solids," Nucl. Mat. Meas. 8 (1979) 344-355.

10 Abhold, M. E., et al., "Survey of Seven Measurement Techniques for Quantifying the Fissile Content of Spent Fuel," Report LA-UR-07-3336, Los Alamos National Laboratory, Los Alamos, N.M. (2007). 


\section{APPENDIX}

This appendix incorporates INL Report INL/CON-09-16103. INL/CON-09-16103 was prepared in the spring of 2009 and submitted for publication in the proceedings of the $50^{\text {th }}$ annual meeting of the Institute of Nuclear Materials Management in Tucson, Ariz. This paper summarizes simulation and modeling work that examined the neutron emission characteristics of two mixed-oxide (MOX) fuel materials used for testing at INL.

The citation for this report is:

Dolan, J. L., Flaska, M., Pozzi, S. A., and Chichester, D. L., "Measurement and Characterization of Nuclear Material at Idaho National Laboratory," Report INL/CON-09-16103, Idaho National Laboratory, Idaho Falls, Idaho (2009). 


\title{
Measurement and Characterization of Nuclear Material at Idaho National Laboratory
}

\author{
J. L. Dolan ${ }^{1}$, M. Flaska ${ }^{1}$, S. A. Pozzi ${ }^{1}$, and D. L. Chichester ${ }^{2}$ \\ ${ }^{I}$ Department of Nuclear Engineering \& Radiological Sciences, University of Michigan, Ann Arbor, MI 48109 \\ ${ }^{2}$ Idaho National Laboratory, Idaho Falls, ID 83415
}

\begin{abstract}
A measurement plan and preliminary Monte Carlo simulations are presented for the investigation of well-defined mixed-oxide fuel pins. Measurement analysis including pulse-height distributions and time-dependent cross-correlation functions will be performed separately for neutrons and gamma rays. The utilization of Monte Carlo particle transport codes, specifically MCNP-PoliMi, is discussed in conjunction with the anticipated measurements. Four EJ-309 liquid scintillation detectors with an accurate pulse timing and digital, offline, optimized pulse-shape discrimination method will be used to prove the dependency of pulse-height distributions, cross-correlation functions, and material multiplicities upon fuel pin composition, fuel pin quantity, and detector geometry. The objective of the measurements and simulations is to identify novel methods for describing mixed-oxide fuel samples by relating measured quantities to fuel characteristics such as criticality, mass quantity, and material composition. This research has applications in nuclear safeguards and nonproliferation.
\end{abstract}

Keywords: Cross-correlation, Plutonium-oxide, Liquid scintillator, Special nuclear material, MCNP-PoliMi

\section{Introduction}

The need for advanced safeguards techniques to accurately characterize nuclear fuels containing plutonium and other transuranic elements is increasing in demand as the desire to utilize nuclear power as a reliable energy source increases. In this context, fuel reprocessing and advanced fuel recycling are important topics in the nuclear power industry. Mixed-oxide (MOX) fuels utilize plutonium that persists after the use of reactor fuel. Re-use of both plutonium and uranium in the form of MOX fuels offers a significant increase in the amount of total energy produced from the fuel material [1].

Organic scintillation detectors are being increasingly used in systems that are developed to measure both neutrons and gamma rays from fissile materials such as MOX. These detectors function at an appropriate range of energy for neutron detection within this application (typical neutron-measurement range is between $500 \mathrm{keV}$ and $10 \mathrm{MeV}$ ), allowing high-energy neutron detection without moderation [2]. In addition to neutron detection, organic scintillators are sensitive to gamma rays. This dual mode of detection makes organic scintillators viable in applications requiring the detection and characterization of special nuclear material (SNM). Furthermore, liquid scintillators offer the capability to post-process measured data utilizing pulse-shape discrimination (PSD), thus providing an accurate method for distinguishing between neutrons and gamma rays [3]. The PSD method has been established in the past and is based on standard charge-integration method. Specifically, two integrals are calculated for each measured pulse: an integral of the pulse tail and an integral of the total pulse. The two range-optimized integrals allow the calculation of a ratio to distinguish the interacting particle type. 
Recently, a measurement system developed at the University of Michigan (UM) was used to measure plutonium-oxide samples at the JRC in Ispra, Italy: pulse-height distributions (PHDs), cross-correlation functions, and multiplicities were acquired. The amplitude of the PSD-attributed neutron and gamma-ray pulses, which is a function of incident particle energy, is used as the basis for creating PHDs [4]. Cross-correlation functions are derived from differences between the arrival times of two correlated detections [5]. The Monte Carlo particle transport code, MCNP-PoliMi, has the capability to accurately model interactions necessary for these measurements [6]. This paper presents new simulation results of cross-correlations from fresh MOX fuel pins; these crosscorrelations will be measured at the Idaho National Laboratory (INL) in June of 2009 and this novel measurement will result in a large amount of data that will be used to validate Monte Carlo results. The ultimate goal of this measurement is to provide new methods for the detection and characterization of MOX fuel elements that will be accurate, fast, and robust.

\section{Measurement Description}

\section{A. Description of Measurement Set-up}

Figure 1 shows a single EJ-309 detector, secured to its height-adjustable holder. The measurements will be performed using four EJ-309 liquid scintillation detectors. The detectors will be placed horizontally in $90^{\circ}$ intervals around a MOX sample, with each detector equidistant from the sample (see MCNP-PoliMi model in Figure 3a). Lead bricks will surround a MOX fuel pin assembly as necessary to appropriately attenuate the fuel assembly's gamma-ray background. A CAEN V1720, 8-channel, 12-bit, 250-MHz digitizer with real-time sampling capability will be used to digitize and store measured pulses. Each of the four channels provides time-synchronized pulse information which is collected only when exceeding the applied $70 \mathrm{keVee}$ (keV electron equivalent) light output threshold (corresponding to approximately $450 \mathrm{keV}$ neutron deposited energy). This digital data acquisition system enables the implementation of pulse-height and time correlation algorithms enhanced by optimized offline PSD methods [3].

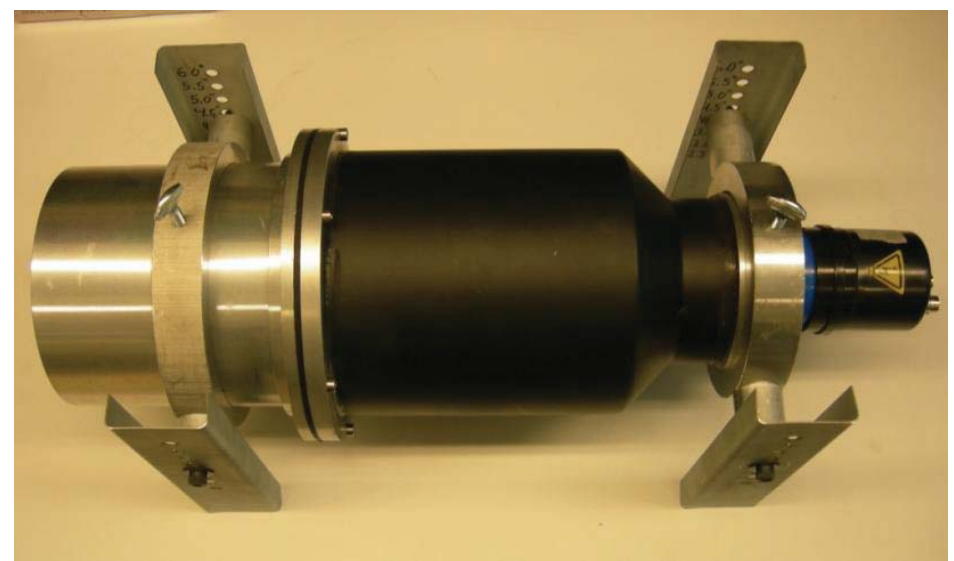

(a)

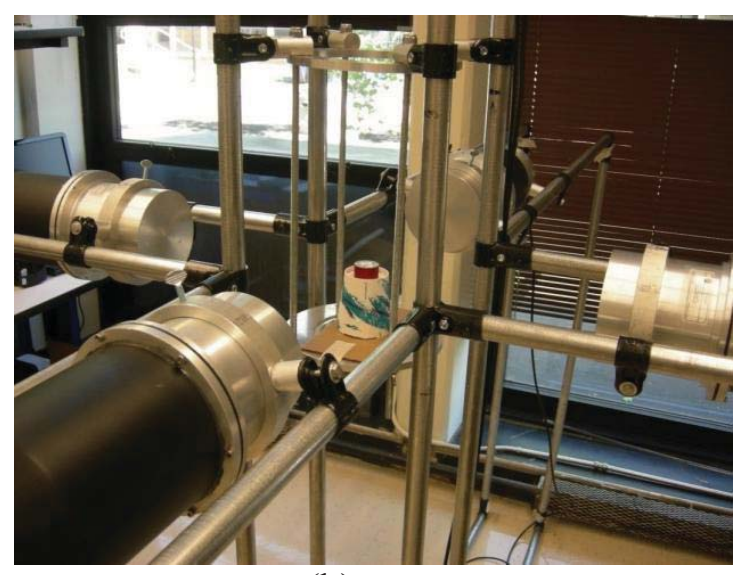

(b)

Figure 1. a) EJ-309 liquid scintillation detector with height-adjustable stand, b) Detector geometry for cross-correlation measurements of ${ }^{252} \mathrm{Cf}$

The detectors were calibrated to the same gain using a ${ }^{137} \mathrm{Cs}$ source. The data acquisition system was tested using a $12-\mu \mathrm{Ci}{ }^{252} \mathrm{Cf}$ neutron source as well as a $1-\mathrm{Ci} \mathrm{Pu}-\mathrm{Be}$ neutron source. 
Two MOX pin types will be measured at INL jointly by UM and INL personnel. The measurements will be performed with a measurement system developed at UM to measure PHDs, cross-correlation functions, and multiplicities. The dependence of these measured quantities on fuel pin composition, fuel pin quantity, and detector geometry will be determined. The material compositions of the pins are shown in Table 1 where a notable difference can be observed between the pins in the mass of ${ }^{240} \mathrm{Pu}$. This isotope is the strongest spontaneous-fission neutron source in the MOX pins. In addition to dependence upon fuel pin material composition, the ability to detect differences in fuel pin quantity will also be assessed. The measurements will be performed on a quantity of approximately 100 fuel pins (equivalent to approximately $1 \mathrm{~kg}$ of plutonium), for the two fuel types, and an additional configuration of approximately 50 fuel pins will be available for one of the fuel types. The final measurements will be performed with varying sample-detector distance.

Table 1. Isotopic compositions of two MOX fuel pin types at the INL [8].

\begin{tabular}{ccc}
\hline \hline Isotope & $\begin{array}{c}\text { Pin \#1 } \\
\text { (wt. \%) }\end{array}$ & $\begin{array}{c}\text { Pin \#2 } \\
\text { (wt. \%) }\end{array}$ \\
\hline${ }^{238} \mathrm{Pu}$ & 0.01 & 0.01 \\
${ }^{239} \mathrm{Pu}$ & 11.42 & 10.98 \\
${ }^{240} \mathrm{Pu}$ & $\mathbf{1 . 5 3}$ & 4.10 \\
${ }^{241} \mathrm{Pu}$ & 0.17 & 0.58 \\
${ }^{242} \mathrm{Pu}$ & 0.02 & 0.02 \\
${ }^{241} \mathrm{Am}$ & 0.06 & 0.16 \\
${ }^{235} \mathrm{U}$ & 0.17 & 0.16 \\
${ }^{238} \mathrm{U}$ & 74.78 & 72.13 \\
$\mathrm{O}$ & 11.85 & 11.86 \\
\hline \hline
\end{tabular}

\section{B. Data Analysis and Expected Results}

The measured data will be processed by optimized, offline, digital PSD techniques. The data acquired during each measurement configuration of the MOX fuel pin assemblies will be processed to obtain PHDs and cross-correlation functions.

The amplitude of the PSD-attributed neutron pulses is strongly related to the incident neutron energy. Despite this relationship, when using organic scintillation detectors, the resulting PHDs require the use of spectrum unfolding to obtain incident neutron energy spectra. Additionally, time of flight (TOF) measurements can be used to confirm neutron energy spectra obtained through PHDs and Monte Carlo simulations. Measured energy distributions provide insight into the presence of oxide in a mixed-oxide fuel pin assembly. For this purpose, the presence of valleys in the unfolded energy spectra, significance of $(\alpha, n)$ contributions, and changes in the average detected neutron energy are employed as discussed in Section 3. The average detected energy provides information with regards to the quantity of fuel pins within the assembly.

Timing information will be used to calculate cross-correlation functions and material multiplicity. Separate contributions to total cross-correlation functions (i.e. neutron-neutron, gamma-ray-neutron, etc.) are identified through PSD and provide information that is unique to the sample's material composition, constituent activity, and structural geometry. Relationships will be formulated, connecting correlation measurements and multiplicity analysis with quantities such as material criticality, mass quantification, and sample composition. 


\section{Monte Carlo Analysis}

\section{A. MCNP-PoliMi Description}

Many Monte Carlo simulations of nuclear processes utilize interaction physics in conjunction with stochastic particle transport. Examples are the MCNP codes. However, MCNP does not incorporate the correlated particle detection required in several SNM-characterization applications. MCNP-PoliMi is a modified version of the MCNP4C code developed in order to obtain these timecorrelated quantities - specifically the correlation between neutron interactions and their consequent gamma-ray production. MCNP-PoliMi utilizes a unique event-by-event modeling technique that does not stray from physical reality by using non-analog physics, unlike MCNPX [7].

The latest version of MCNP-PoliMi, version 1.2.5, incorporates the ability of simulating all standard MCNP sources with additional custom sources. These novel sources, such as ${ }^{240} \mathrm{Pu}$ and ${ }^{242} \mathrm{Pu}$ spontaneous-fission sources include spontaneous-fission distributions with specific multiplicity distributions. Additionally, $(\alpha, n)$ distributions are source options for situations involving plutonium isotopes in oxides. All spontaneous-fission sources and $(\alpha, n)$ sources from the isotopes shown in Table 1 were modeled. Figure 2 shows the contributions of the sources to the neutron production rate.

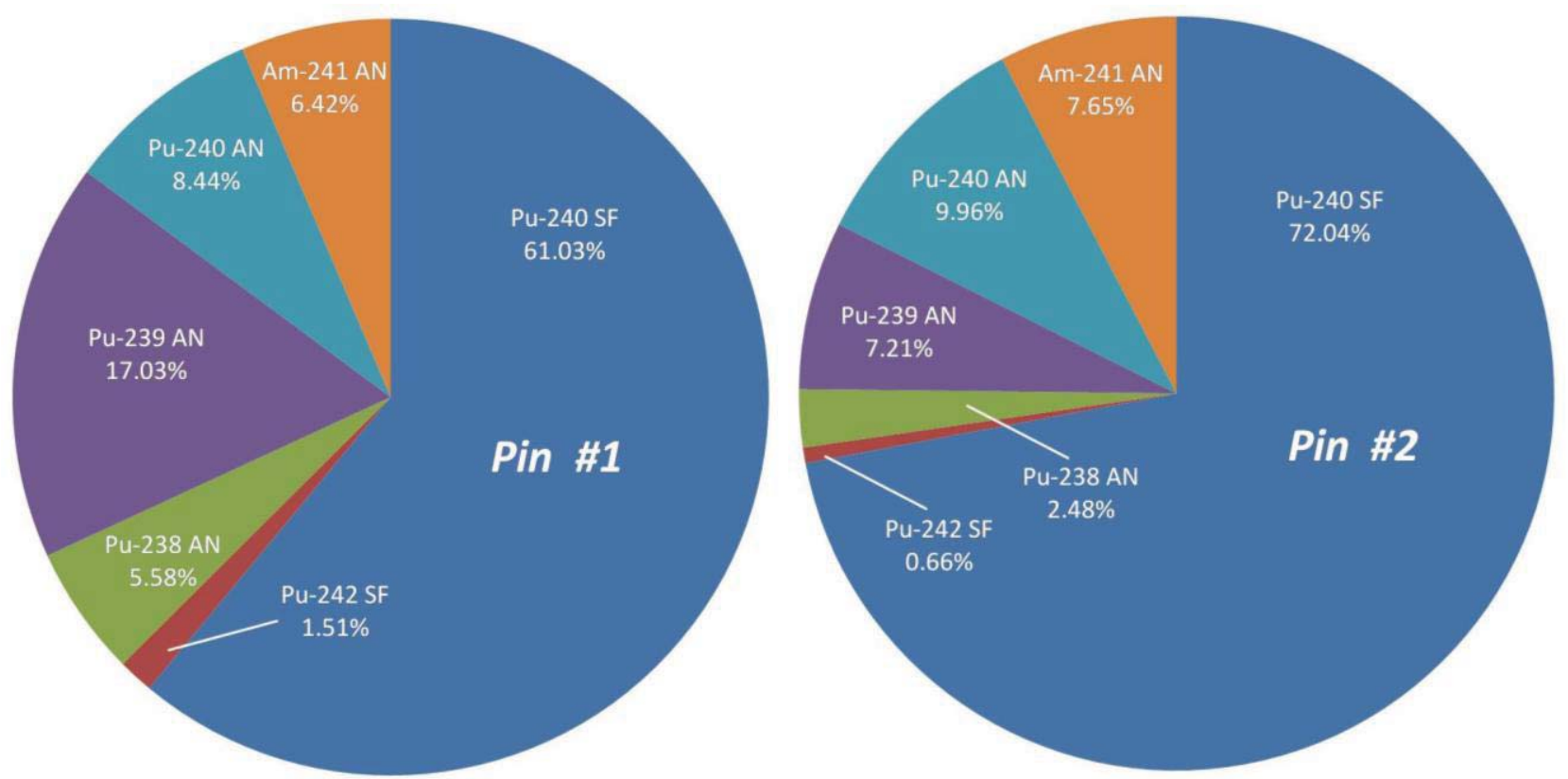

Figure 2. Contributions of spontaneous fission and $(\alpha, n)$ neutron sources present in the INL MOX fuel pins to the total neutron .

The data outputs from MCNP-PoliMi simulations include details about each individual interaction that took place in the detector. The data are subsequently post-processed and tailored to anticipate a particular detector's response. These simulations of well-defined INL MOX fuel pins provide the information necessary to obtain PHDs, cross-correlation functions, and multiplicities. A light-output threshold of $70 \mathrm{keVee}$ is used in post-processing to discard any neutron that creates a pulse that does not produce enough light to be detected in a practical situation. 


\section{B. Description of Monte Carlo Models}

The MCNP-PoliMi model of the proposed measurement set-up includes four EJ-309 liquid scintillation detectors which are placed around the axis of the MOX fuel pin set-up, with each detector equidistant from the source, as shown in Figure 3a. Parameters that are adjusted during the simulations include the composition of the fuel pins (two pin types), the distance between the detectors $(30 \mathrm{~cm}$ and $60 \mathrm{~cm})$ and the number of pins under investigation (50 and 100 pins).

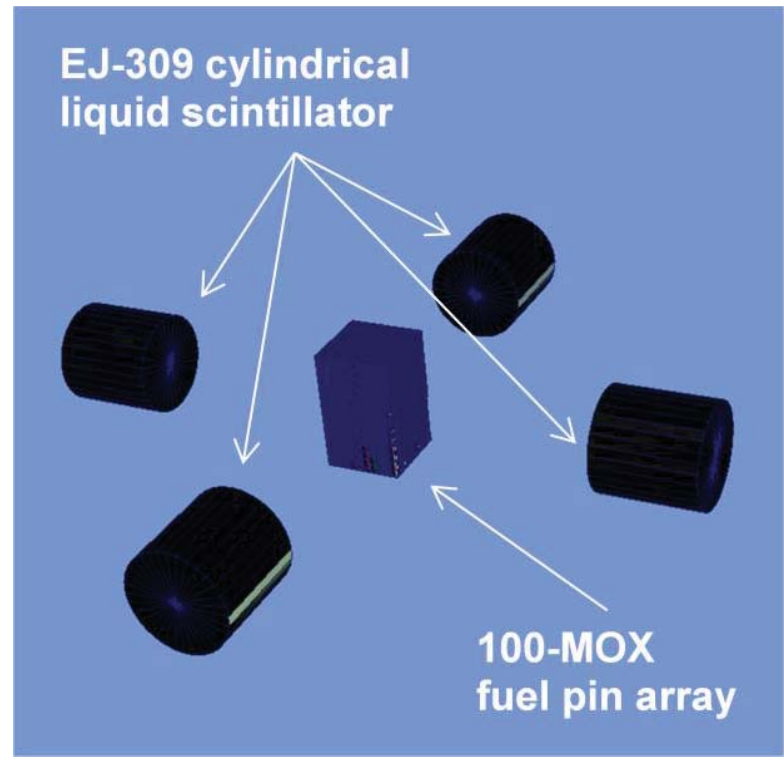

(a)

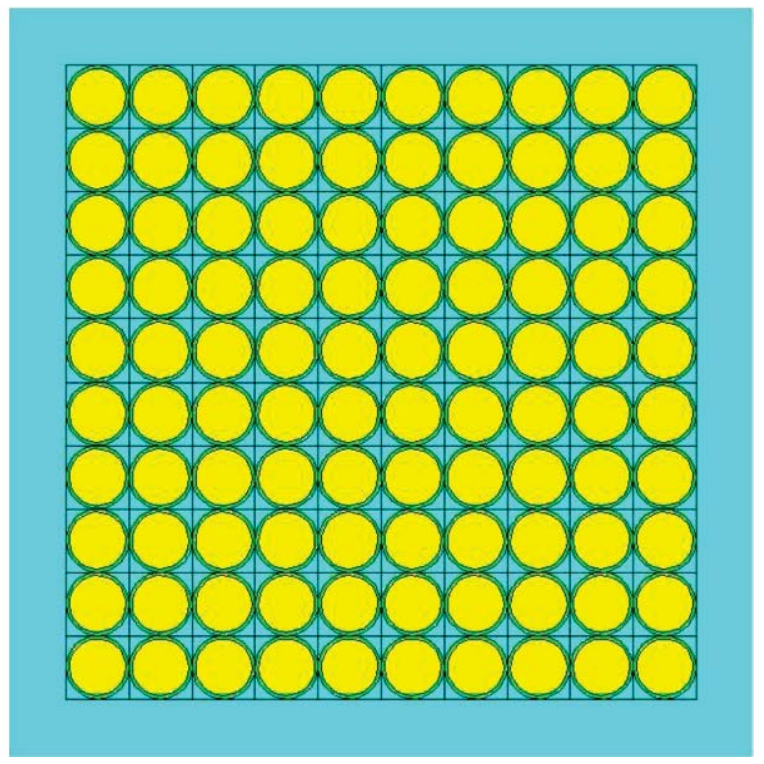

(b)

Figure 3. a) Three-dimensional MCNP-PoliMi model including four EJ-309 cylindrical liquid scintillators $30 \mathrm{~cm}$ from the axis of the fuel pin array, b) Two-dimensional depiction of the MCNP-PoliMi model of the centrally located array of 100 MOX fuel pins where yellow represents fuel and green zirconium cladding.

All measurements scenarios were simulated with the MCNP-PoliMi code in order to determine dependence of PHDs, cross-correlation functions, and multiplicities upon sample type. The sources simulated in MCNP-PoliMi were two varieties of MOX fuel pins with different isotopic compositions, as outlined in Table 1 and Figure 2 [9]. The neutrons and gamma rays emitted from each pin originate from the individual spontaneous fissions seen in plutonium or $(\alpha, n)$ reactions occurring in the presence of oxygen. All six source contributions in Figure 2 were modeled individually. The reported results are then the summation of the products of the six simulation results with their reaction probabilities. Exact fuel pin geometry and cladding material are specified in the literature and included into the model [8].

\section{Simulation Results}

Initial simulation results included the neutron energy distributions for various numbers of pins and the detector response: PHDs and cross-correlation functions. 


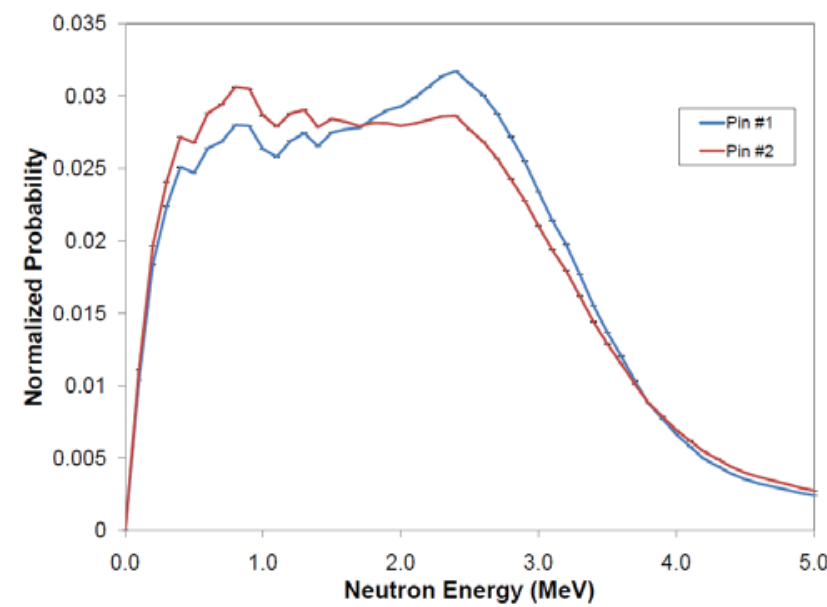

(a)

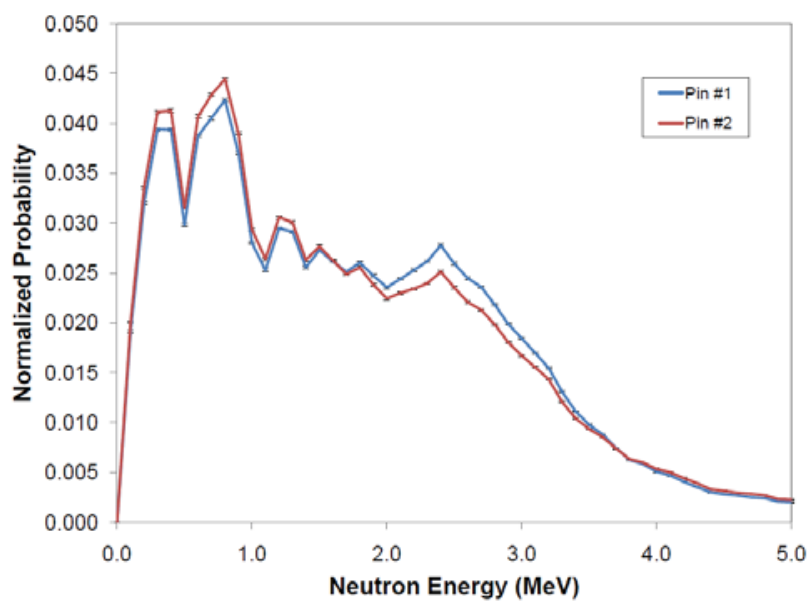

(b)

Figure 4. a) MCNP-PoliMi simulated neutron energy spectra incident on the face of the detector for a single MOX fuel pin, b) MCNP-PoliMi simulated neutron energy spectra incident on the face of the detector for a 100-pin MOX fuel assembly.

Figure 4a shows the energy distributions of the neutrons incident upon the detector from an individual MOX fuel pin for both pin types. Figure $4 \mathrm{~b}$ shows the neutron energy distributions for 100-pin assemblies. Self-shielding and multiplication effects significantly alter the general shape of the neutron energy spectra in comparison to the single pin case. The valleys located in the lower energy region of the spectra, specifically near $0.05 \mathrm{MeV}, 0.1 \mathrm{MeV}$, and $1.3 \mathrm{MeV}$, are due to energy resonances in the neutron elastic scattering cross-section for ${ }^{16} \mathrm{O}$, which is shown in Figure 5 [10]. Simulations were also performed to determine that neutron energy distributions are a strong function of pin quantities with respect to both the shape of the spectra (Figure 6a) and average energy values (Figure 6b).

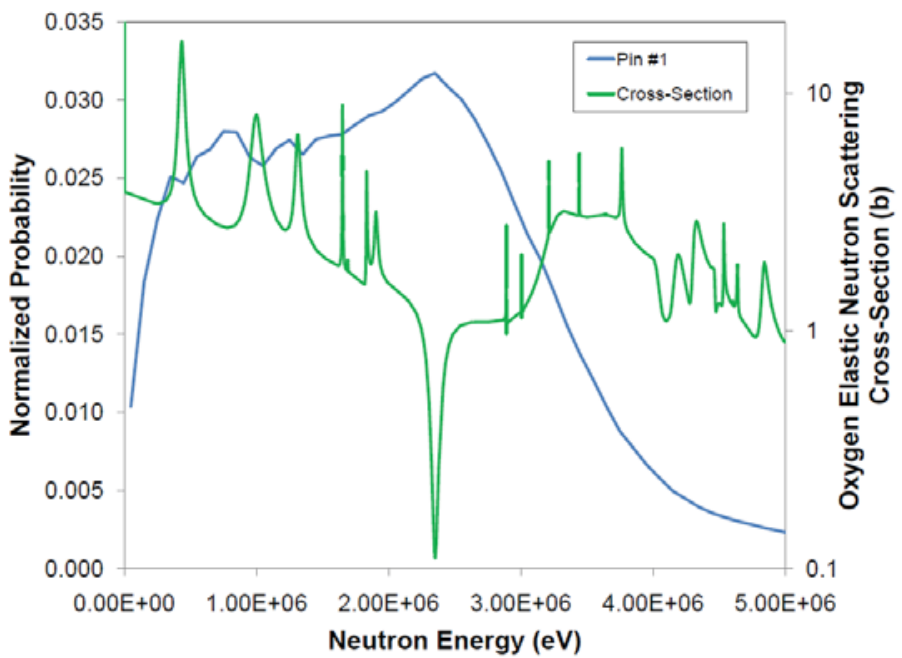

Figure 5. Comparison of the MCNP-PoliMi simulated neutron energy spectrum tallied on the face of the detector for a single MOX fuel pin type \#1 and the elastic neutron scattering cross-section on ${ }^{16} \mathrm{O}$. 


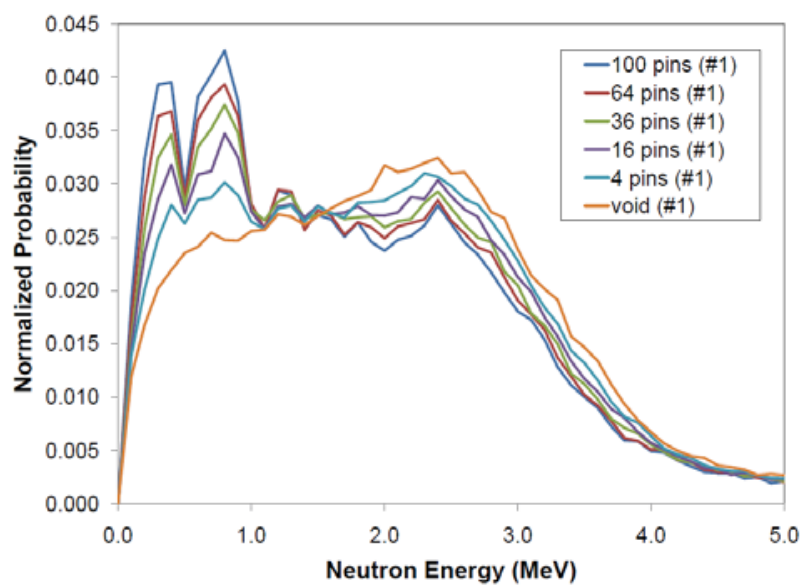

(a)

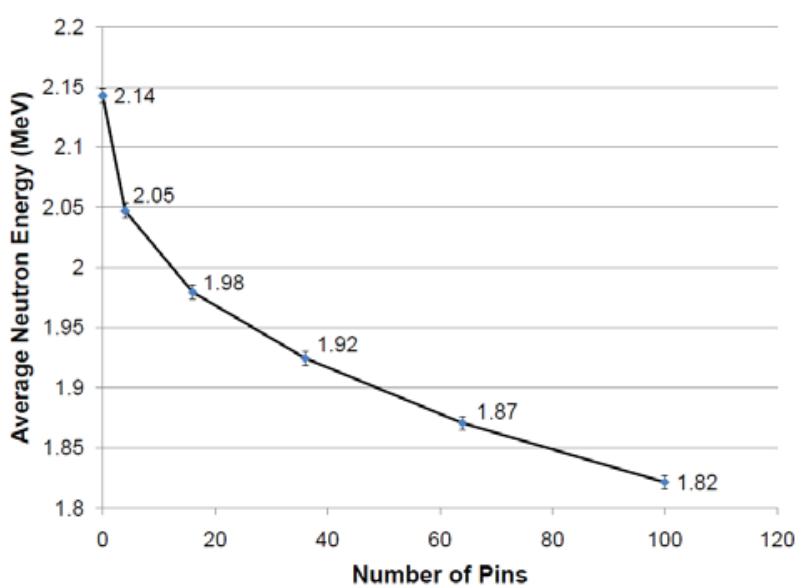

(b)

Figure 6. Neutron energy spectrum (a) and average detected neutron energy (b) as a function of the quantity of fuel pins (type \#1) included in the assembly.

Time-dependent cross-correlation functions were generated from the simulation data output with a MCNP-PoliMi post-processor. Total cross-correlation functions for assemblies of both pin type \#1 and \#2 are shown in Figure 7. For correlations detected with time differences of -40 ns to 40 $\mathrm{ns}$, it is anticipated that a 100-pin assembly of type \#1 will produce approximately 18 crosscorrelations per second (ccs/s); and a 100-pin assembly of type \#2 will produce approximately 47 $\mathrm{ccs} / \mathrm{s}$. The shape of the curves are quite similar for the pin type comparison in Figure 7, although the relative amount of ccs/s varies significantly due to pin type \#2's larger abundance of ${ }^{240} \mathrm{Pu}$.

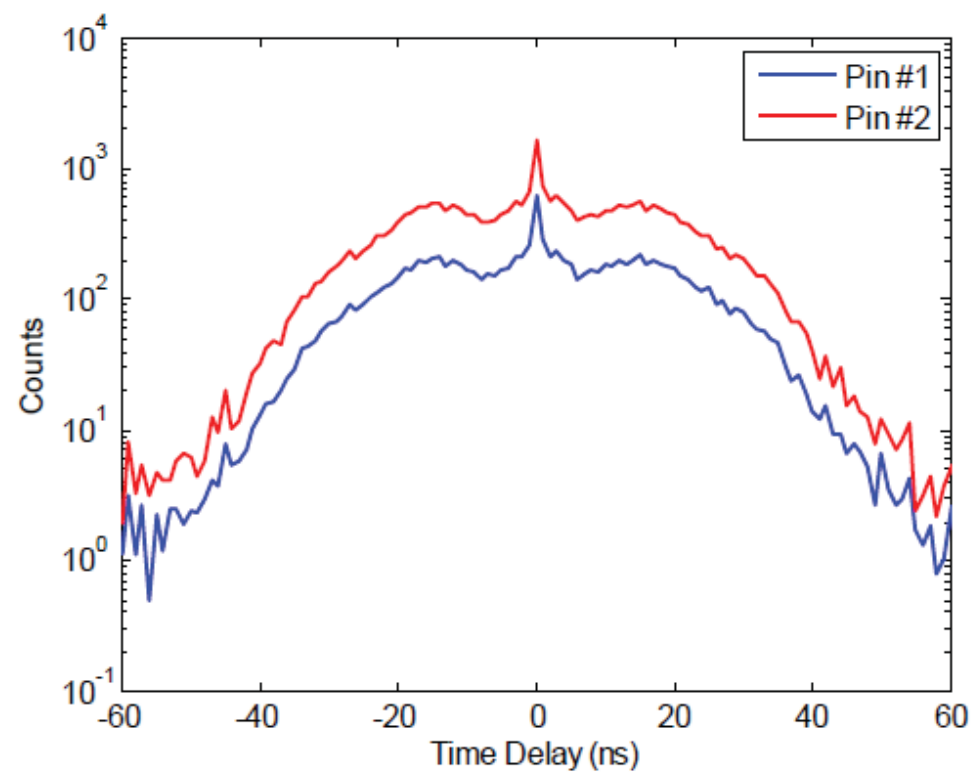

Figure 7. Comparison of the MCNP-PoliMi simulated total cross-correlation functions for pins \#1 and \#2 in a 10minute acquisition time.

Each total cross-correlation curve from Figure 7 can be broken down into individual contributions as shown in Figure 8. Specific correlation curves such as the neutron-neutron curve can be used to study concepts such as multiplicity and criticality. The total cross-correlation 
functions as a function of pin quantity are shown in Figure 9a. Integrating these total correlation curves provides valuable information on parameters such as mass quantification; Figure 9b shows the relationship between pin quantity and the number of cross-correlations per second.

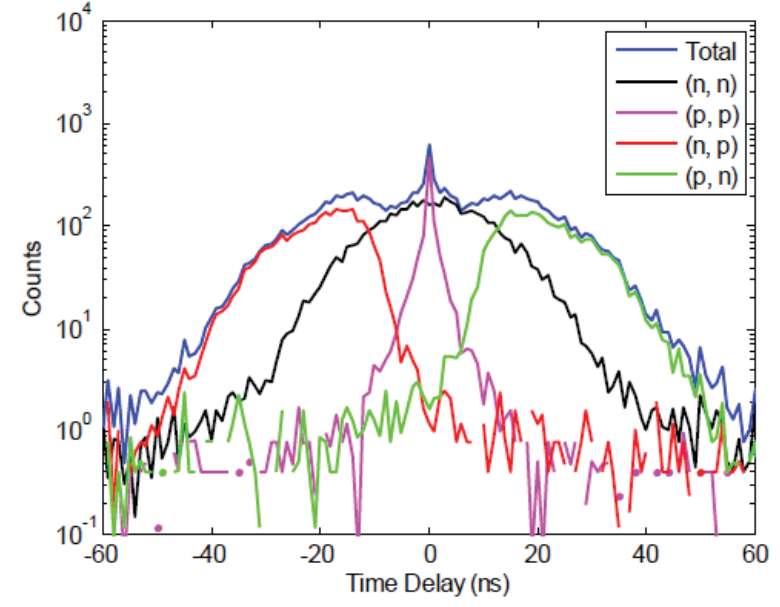

(a)

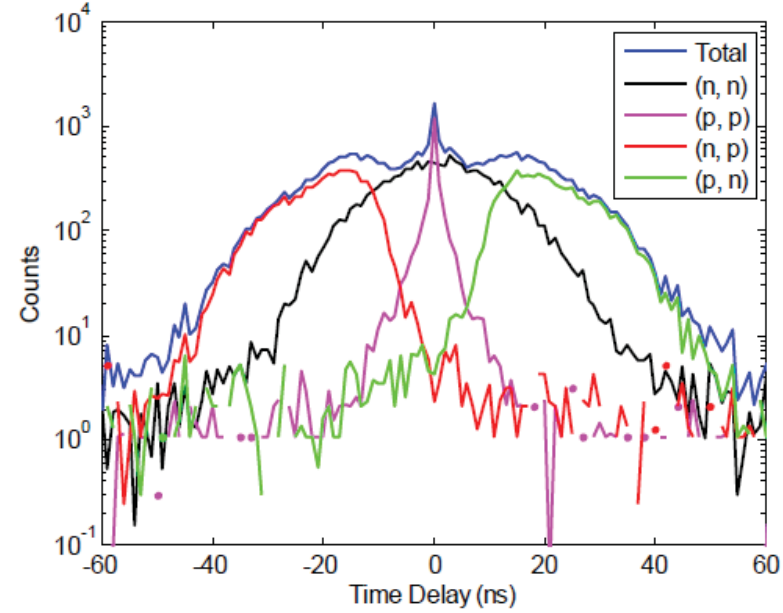

(b)

Figure 8. Breakdown view of cross-correlation functions showing the individual correlation contributions for pins $\# 1$ (a) and \#2 (b). The simulations were normalized to a 10-minute acquisition time.

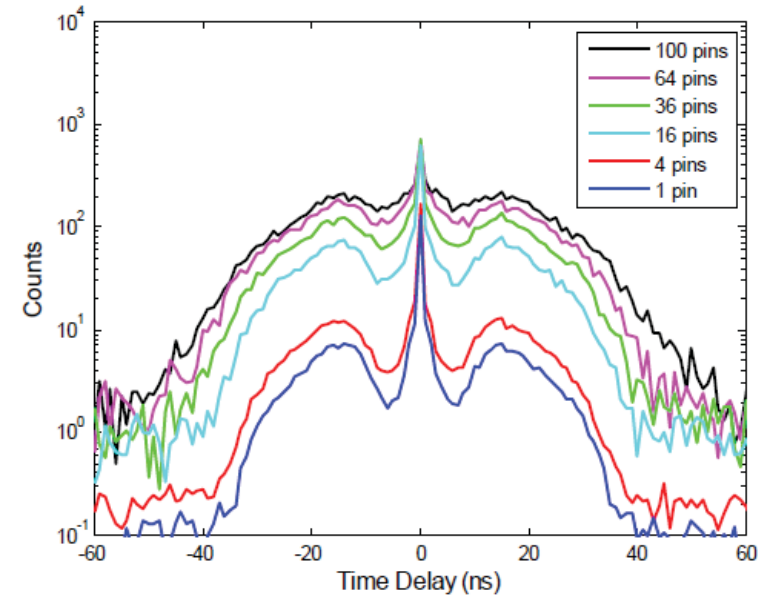

(a)

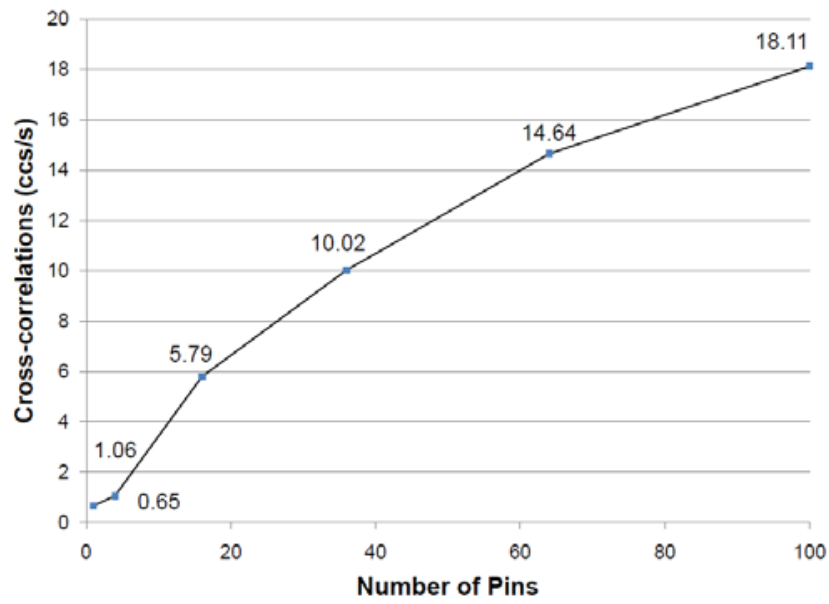

(b)

Figure 9. a) MCNP-PoliMi simulated total cross-correlation functions for different pin quantities for a 10-minute acquisition time, b) trend in total cross-correlations per second for different pin quantities.

The presented correlations result from a combination of six simulations, originating from spontaneous fission and $(\alpha, n)$ reactions that are present in MOX fuel. Pin type \#1 acquires approximately $90 \%$ of its correlations from the spontaneous fission sources and $10 \%$ as a result of the $(\alpha, n)$ sources. Pin type \#2 acquires approximately $93 \%$ of its correlations from the spontaneous fission sources and $7 \%$ as a result of the $(\alpha, n)$ sources. This is expected because pin type \#2 contains more ${ }^{240} \mathrm{Pu}$ than pin type \#1. The passive detection of oxygen in plutonium is made possible by the $(\alpha, n)$ reactions which alter the shape of the cross-correlation functions, primarily the neutron-gamma and gamma-neutron components of the correlation curves. 


\section{Conclusions}

This paper presented new simulation results for MOX fuel pin assemblies that will be measured at the Idaho National Laboratory in June, 2009. The experimental set-ups were derived from detailed Monte Carlo modeling which incorporated accurate detector response functions. We presented a detailed model of the neutron source from the MOX fuel, which includes spontaneous fission and $(\alpha, n)$ contributions. The neutron energy spectrum incident on the detectors for a varying number of fuel pins was determined. Neutron and gamma-ray cross-correlation functions were simulated for a varying number of pins. The separate contributions to these correlation functions were discussed and analyzed. The results show that this type of measurement can be used to distinguish the two pin types and to determine the mass (or number of pins) of the assembly. In addition to developing an experimental methodology, this study will be used as a basis for the future validation of the MCNP-PoliMi code for modeling MOX type fuel assemblies.

Future work will consider a more customized methodology in experimentally distinguishing MOX fuels. Relation between measured pulse-height distributions and cross-correlation functions, and quantities such as material criticality, mass quantification, and sample composition will be assessed in detail.

\section{Acknowledgements}

This work was supported by the U.S. Department of Energy Office of Nuclear Energy and the Advanced Fuel Cycle Initiative Safeguards Campaign. Idaho National Laboratory is operated for the U.S. Department of Energy by Battelle Energy Alliance under DOE contract DE-AC07-05ID14517.

\section{References}

1. "MOX, Mixed Oxide Fuel: WNA." World Nuclear Association. <http://www.worldnuclear.org/info/inf29.html>. 2009.

2. Eljen Technologies. EJ-309 Liquid Scintillator Pulse-Shape Discrimination Properties.

3. M. Flaska, S.A. Pozzi, Nucl. Instr. and Meth. A 577, pp. 654-663, 2007.

4. S.A. Pozzi, S.D. Clarke, M. Flaska, P. Peerani. Pulse-Height Distributions of Neutron and Gamma Rays from Plutonium-Oxide Samples. Submitted March 2009.

5. S.D. Clarke, et al., Nucl. Instr. And Meth. A. 2009.

6. S.A. Pozzi, E. Padovani, and M. Marseguerra. MCNP-PoliMi: A Monte Carlo Code for Correlation Measurements, Nucl. Instr. Meth. A, 513, pp. 550-558. 2003.

7. X-5 Monte Carlo Team. MCNP - A General Monte Carlo N-Particle Transport Code, Version 5, vols 1 - 3. Los Alamos National Laboratory. LA-UR-03-1987, LA-CP-03-0245, and LA-CP03-0284. 2003

8. R.T. Klann, B.D. Austin, S.E. Aumeier, and D.N. Olsen. Inventory of Special Nuclear Materials from the Zero Power Physics Reactor, Nuclear Technology Division at Argonne National Laboratory-West. ANL-NT-176. 2001.

9. Reily, Doug, Norbert Ensslin, and Hastings Smith Jr. Passive Nondestructive Assay of Nuclear Materials. Ts. Los Alamos National Laboratory, Los Alamos, NM. 1991.

10. Evaluated Nuclear Data File. Brookhaven National Laboratory. ENDF/B-VII.0, USA. $<$ http://www.nndc.bnl.gov/sigma/>. 2006. 